\title{
Effect of herbicide (Quizalofop-p-ethyl) on growth, photosynthetic pigments, enzymes and yield responses of Blackgram (Vigna mungo L.)
}

\author{
T. Mahakavi ${ }^{1}$, R. Bakiyaraj ${ }^{1}$, L. Baskaran ${ }^{1, *}$, Nusrat Rashid ${ }^{1}$, K. Sankar Ganesh ${ }^{2}$ \\ ${ }^{1}$ Department of Botany, Annamalai University, Annamalainagar, Chidambaram, India \\ ${ }^{2}$ Department of Botany, A.V.C. College, Mannampandal, Mayilladuthurai, India \\ *E-mail address: basubotany@rediffmail.com
}

\begin{abstract}
The recent experiment was conducted to assess the effect of herbicide (quizalafop-p-ethyl) on growth, photosynthetic pigments, enzymes and yield of Black gram (Vigna mungo L.) during the summer season 2013-2014. This experiment comprised black gram (variety ADT 3) and different concentrations of herbicide (quizalafop-p-ethyl) treatments compared with control. Reduction in growth, photosynthetic pigments, enzymes and yield parameters were observed with $0.5 \%$ herbicide application followed by $1 \%, 1.5 \%$ and $2 \%$, out of all treatments $0.5 \%$ shows least reduction. Thus, $0.5 \%$ herbicide application is the safest way for weed control in Black gram field as it showed least adverse effect on growth, photosynthetic pigments, enzymes and yield of crop when compared with other treatments.
\end{abstract}

Keywords: Vigna mungo L.; herbicide; quizalafop-p-ethyl; pigments; catalase; peroxidase

\section{INTRODUCTION}

The problems of environment can be classified into the following subheads as most of the problems can be traced to one or more of the following either directly or indirectly: Waste generation (sewage, wastewater, kitchen waste, industrial waste, effluents, agricultural waste, food waste) and use of chemicals for various purposes in the form of insecticides, pesticides, chemical fertilizers, toxic products and by-products from chemical industries). Waste generation is a side effect of consumption and production activities and tends to increase with economic advance. What is of concern is the increased presence of toxic chemicals such as halogen aliphatics, aromatics, polychlorinated biphenyls and other organic and inorganic pollutants which may reach air, water or soil and affect the environment in several ways, ultimately threatening the self-regulating capacity of the biosphere (Sen and Chakrabarti 2009; Prasad et al. 2010; Beltrame et al. (2010). Bunce (1993) wrote in 1993”It is useful to keep in mind the concept that a pollutant is a substance in the wrong place, at the wrong time, or in the wrong amount". While herbicides are very important to agriculture, under certain circumstances they may act as pollutants that can deteriorate soils, ground waters and surface waters. While most herbicides are not intentionally applied onto soil, they can enter the soil 
environment from direct interception of spray by the soil surface during early season or postharvest applications. The herbicide concentration may vary from a $5 \mu \mathrm{g}$ to $\mathrm{mg}$ per $\mathrm{kg}$ soil, as most of the applied chemical is retained within the top $5 \mathrm{~cm}$ of soil. Soil is one of the main regulators of herbicide mobility in the environment. Many chemical and biological processes that determine the retention or transport of herbicides take place on the soil surface.

Black gram (Vigna mungo L.) is an important legume crop cultivated worldwide in tropical and subtropical regions of the world and is valued for high protein in its seeds. India is the largest producer and consumer of black gram in the world. Existence of genotypic variability for stress tolerance was reported by many workers in pulse crops viz. black gram and green gram (Baroowa et al., 2012). Black gram (Vigna mungo L.) is one of the important pulse crops in Tamil Nadu which is grown under irrigated, rain fed and rice fallow conditions i.e. relay cropping after rice crop. Weeds compete for water, nutrients, space and cause up to 45 per cent yield loss in black gram (Yadav et al., 1997). Weed can be controlled manually which is laborious, time consuming, energy intensive and only possible on small scale. Mechanical means are economical but it controls only inter row weeds, not intra row weeds. In such situations, herbicides offer most ideal, practical, effective and economical means of reducing early weed competition and crop production losses. So, chemical method for controlling weeds is most effective, efficient, up-to-date and time saving (Ashiq et al., 2007). Quizalafop-p-ethyl (ethyl (RS)-2-(4-6-chloroqinoxolin-2-yloxy) Sphenoxy) Propionate) (CAS No.76578-14-8) belonging to chemical family aryloxyphenoxy, is a selective grass killer for control of many annual and perennial grass weeds, pampas grass, couch, wild oats, volunteer cereals, indian doab, onion twitch, ryegrasses etc, in both legume and non-legume crop production. Its mode of action on the target plants is through the inhibition of fatty acid synthesis. Most of the earlier studies of phytotoxicity of herbicide are generally, restricted to any single crop and comprehensive data assessing the impact of any specific herbicide on more than on legume in parallel is rare. Hence, the present experiment was carried out to find out the optimum level of herbicide (quizalafop-p-ethyl) for efficient growth, photosynthetic pigments, enzymes and yield of Vigna mungo L. (Photo 1).

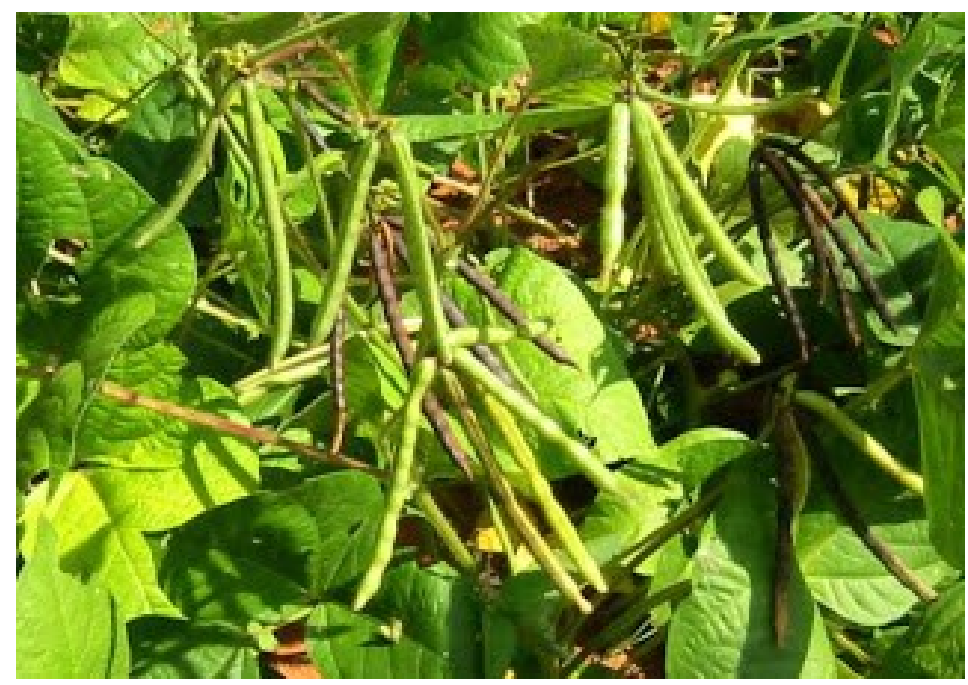

Photo 1. Vigna mungo L. 


\section{MATERIALS AND METHODS}

The experiment was laid out under split plot design with three replications. The treatments consisted of two times (10 and 15 days after sowing) of application in main plot and post emergence herbicide quizalafop-p-ethyl at $0.5 \%, 1 \%, 1.5 \%, 2 \%$ and an absolute control formed the sub pod treatments. The soil of the experimental plot was clay loam with a $\mathrm{pH}$ of 6.2 and having NPK status of medium, medium and low respectively. The black gram variety ADT 3 was sown. The post emergence herbicide quizalafop-p-ethyl was applied using flat-fan nozzle as per treatment schedule. Observation on growth, photosynthetic pigments namely $\mathrm{Chl}$ a, $\mathrm{Chl} b$, enzymes like catalase and peroxidase activities were analyzed from both control and treatments. The yield attributing characters like number of pods/ plant, number of seeds/ plant and 100 seed weight were analyzed from both control and treatments in harvesting stage. The economic analysis was done on the basis of prevailing market prices of inputs used and output obtained in each treatment.

Plant heights were measured in centimeters. Photosynthetic pigments namely Chl a, Chl b, were measured from the fresh leaf by the method of (Arnon et al., 1949).Catalase and peroxidase activity in Black gram leaves was assayed calorimetrically according to method given by Sinha (1872) and Gaksaton and Kaur (1959), Yield attributing characters like Number of pods per plant, seeds per pod and weight of 100 seeds was counted at physiological maturity of plant. Respectively, Statistical significance was assessed at the $\mathrm{p}<$ 0.05 level using one way ANOVA and means were separated by Duncan's multiple range test $(\mathrm{p}<0.05)$ with the help of SPSS 14 software package. Means and standard deviation were calculation from 3 replications.

\section{RESULTS AND DISCUSSION}

Plant treated with quizalafop-p-ethyl (1\%, 1.5 and $2 \%)$ showed significant decrease in plant height (Fig. 1).

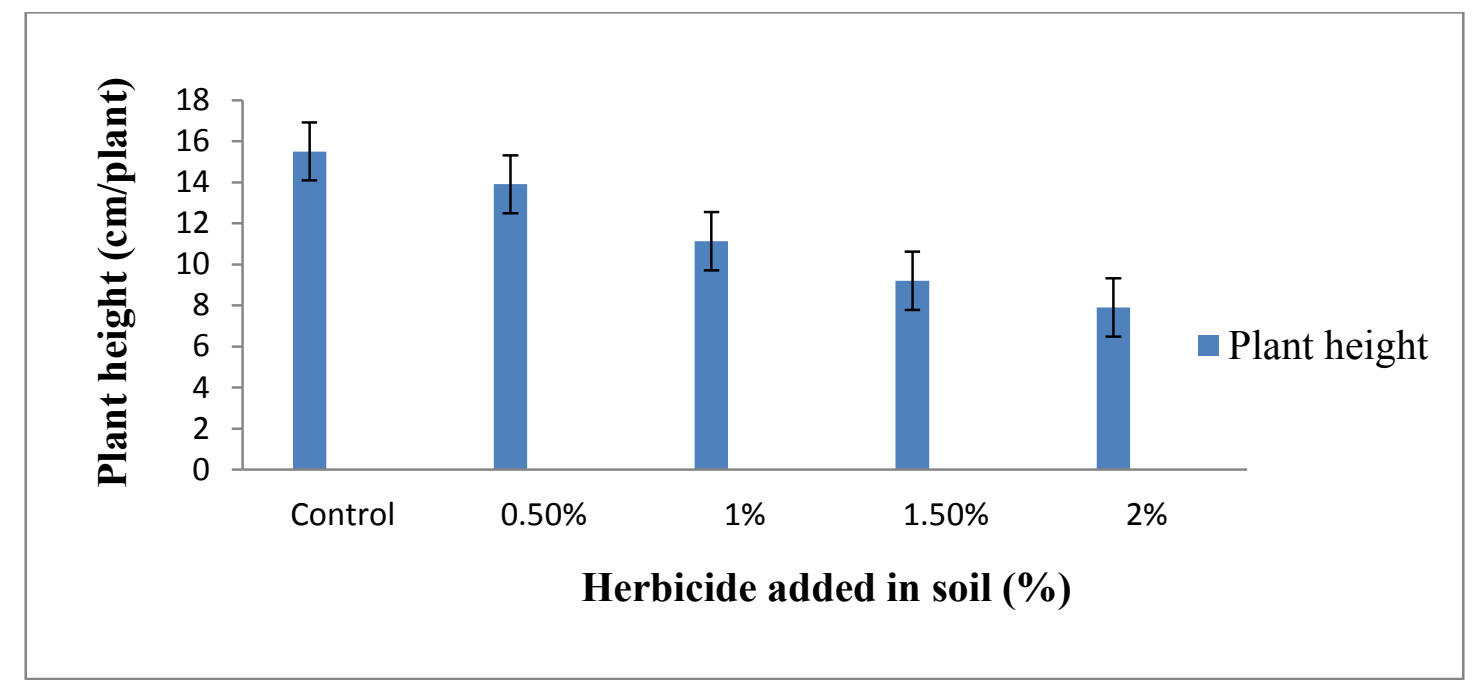

Fig. 1. Effect of different concentrations of herbicide (quizalafop-p-ethyl) on plant height of Vigna mungo L. 
Low concentration of quizalafop-p-ethyl $(0.5 \%)$ stimulated the growth performances of the plant whereas magnitude of decrease in the earlier said parameters was observed under another concentration of quizalafop-p-ethylsolution during the flowering stage (5 DAT) followed by pre-flowering (10 DAT) and post-flowering stages (20 DAT). It was also observed that sulfosulfuron caused least and non-significant decrease in plant height which is supported by results of Davies et al. (2003).

The photosynthetic pigments $\mathrm{Chl} a$ and $\mathrm{Chl} b$ contents increased at lower concentration of quizalafop-p-ethyl which touched maximum during the flowering stage (5 DAT) followed by pre-flowering (10 DAT) and post-flowering stages (20 DAT), (Fig. $2 \& 3$ ) respectively.

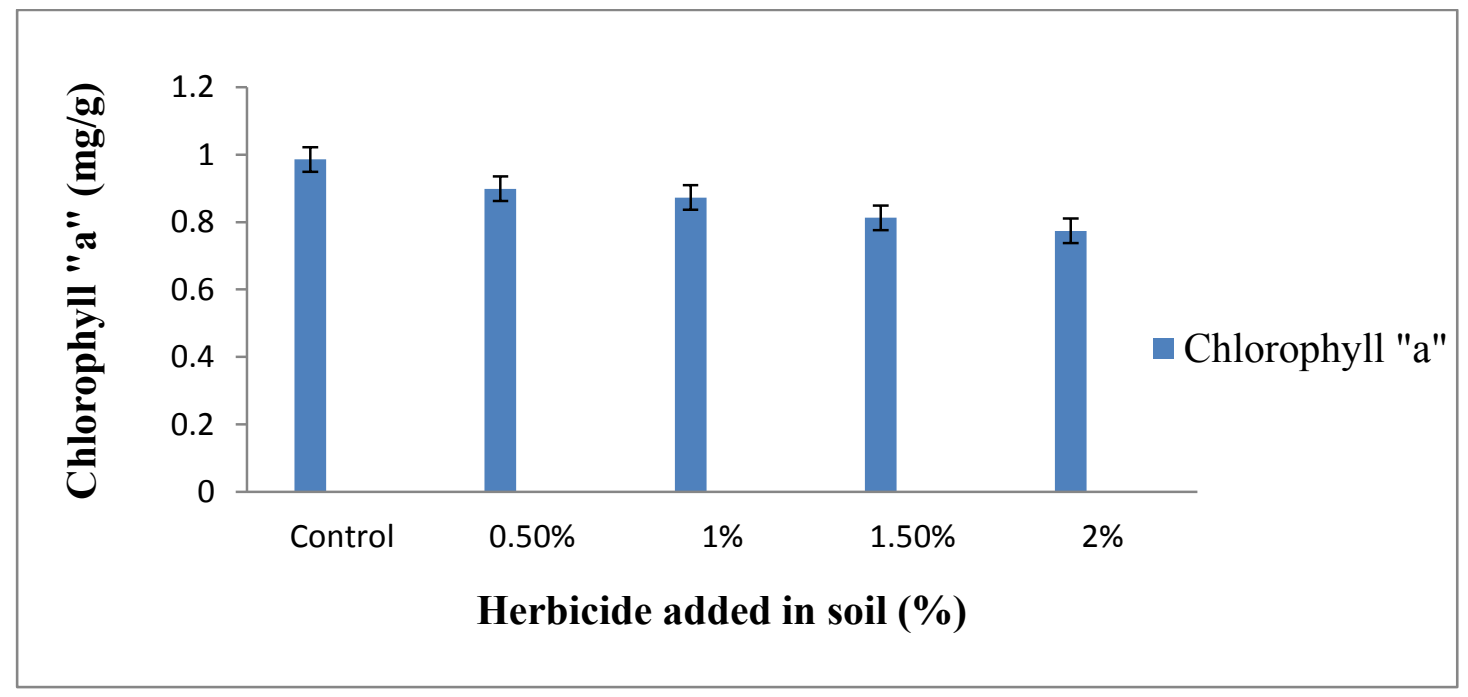

Fig. 2. Effect of different concentrations of herbicide (quizalafop-p-ethyl) on Chlorophyll "a" of Vigna mungo L.

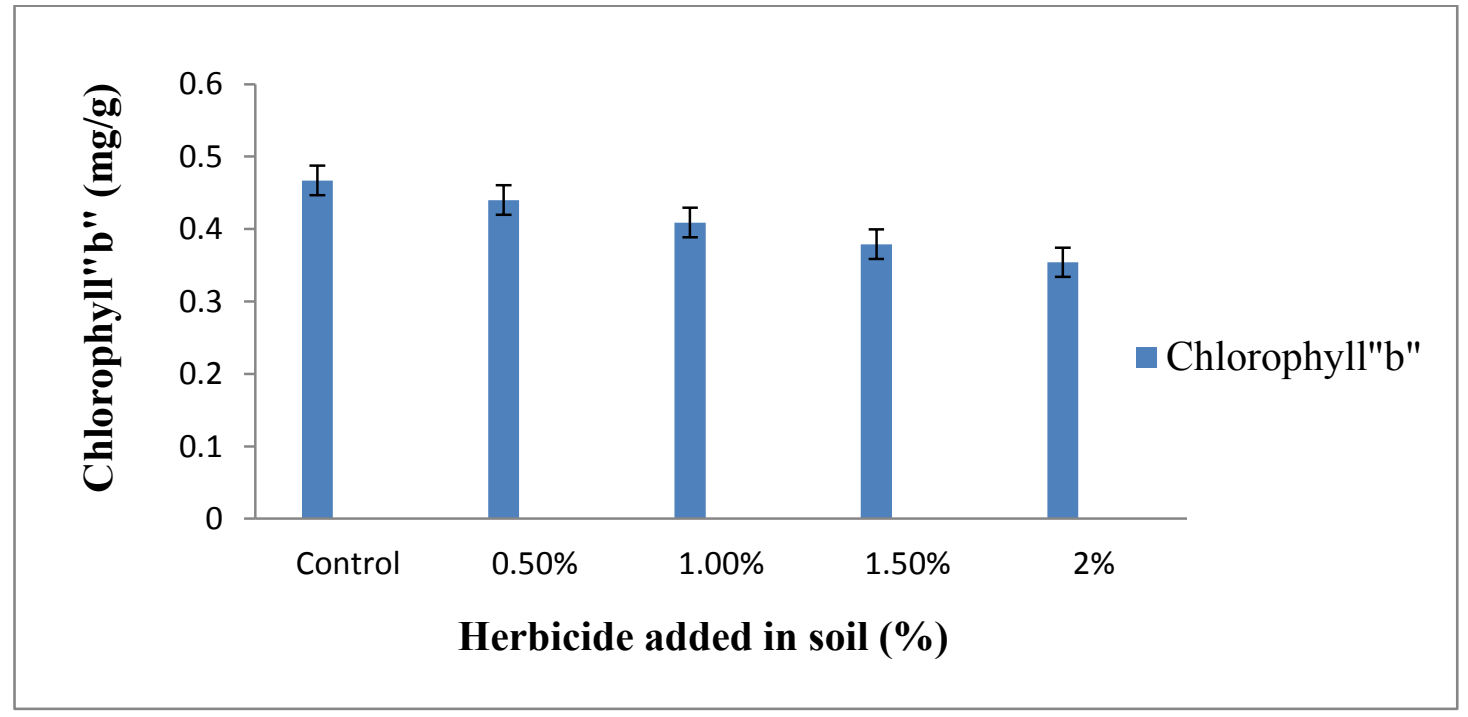

Fig. 3. Effect of different concentrations of herbicide (quizalafop-p-ethyl) on Chlorophyll "b" of Vigna mungo L. 
Further, quizalafop-p-ethyl treatment decreased the photosynthetic pigments in a dose under $0.5 \%, 1 \%, 1.5 \%$ and $2 \%$ quizalafop-p-ethylsolution at flowering stage (5 DAT) followed by pre-flowering (10 DAT) post-flowering stage (20 DAT) over their respective controls. They observed that chl a, chl b and carotenoid contents reached maximum in 15 days after flowering and rapidly decreased after 33 days of flowering. At the post flowering stage, the decrease in the photosynthetic rate as compared to the flowering and pre flowering stages can be attributed to the fact that the ability to photosynthesize increases temporarily and then often, before maturity begins to decrease, which may be because of senescent leaves (Sestak, 1991).

Enzymes like catalase and peroxidase activities increased at lower concentration of quizalafop-p-ethyl which touched maximum during the flowering stage (5 DAT) followed by pre-flowering (10 DAT) and post-flowering stages (20 DAT), (Fig. 4 \& 5) respectively. Further, quizalafop-p-ethyl treatment decreased the catalase and peroxidase activities in a dose under $0.5 \%, 1 \%, 1.5 \%$ and $2 \%$ quizalafop-p-ethyl solution at flowering stage (5 DAT) followed by pre-flowering (10 DAT post-flowering stage (20 DAT) over their respective controls.

Catalase and peroxidase enzyme are considered as reactive oxygen species (ROS) scavenging enzymes in the plant system which split the hydrogen peroxide $\left(\mathrm{H}_{2} \mathrm{O}_{2}\right)$ in to water and oxygen. Super oxide radicals $\left(\overline{\mathrm{O}}_{2}\right)$ and $\mathrm{H}_{2} \mathrm{O}_{2}$ anions are produced in plants under various abiotic and biotic stresses.

These anions are toxic in nature, cause membrane damage and inactivation of various enzymes. Increase in catalase and peroxidase activity in wheat leaves due to herbicide treatments is an indicative of increased detoxification of $\mathrm{H}_{2} \mathrm{O}_{2}$ anions which are produced in response to stress caused by herbicides. Highest expression of both enzymes under is oproturon suggests about its more phytotoxic nature than other herbicides as these enzymes are substrate inducible, their activity increase due to enhanced production of $\mathrm{H}_{2} \mathrm{O}_{2}$ anions. Mohammad et al. (2000) also found an increase in catalase activity in wheat seedlings with herbicide, but found a decrease in peroxidase activity.

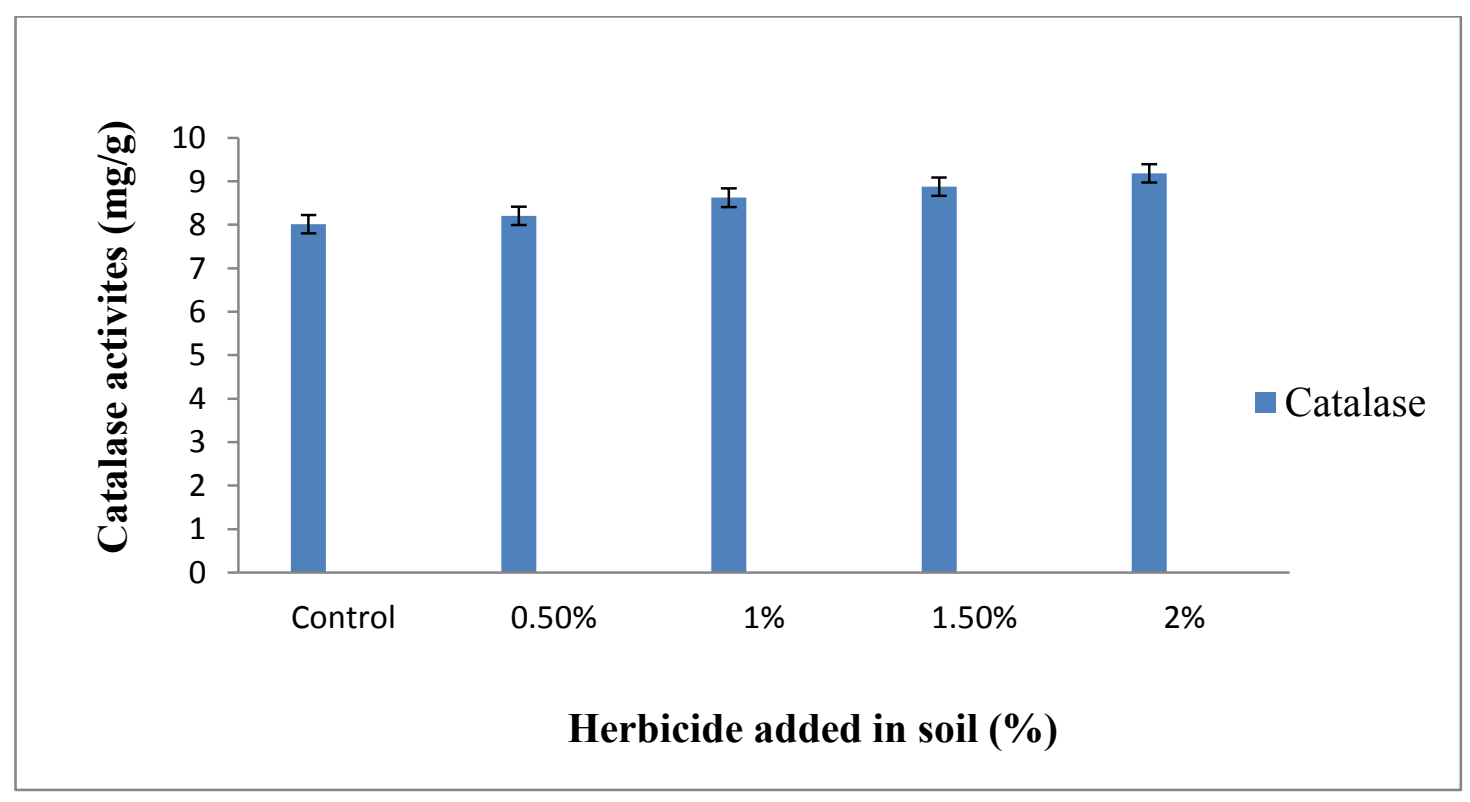

Fig. 4. Effect of different concentrations of herbicide (quizalafop-p-ethyl) on enzymes like Catalase activities of Vigna mungo L. 


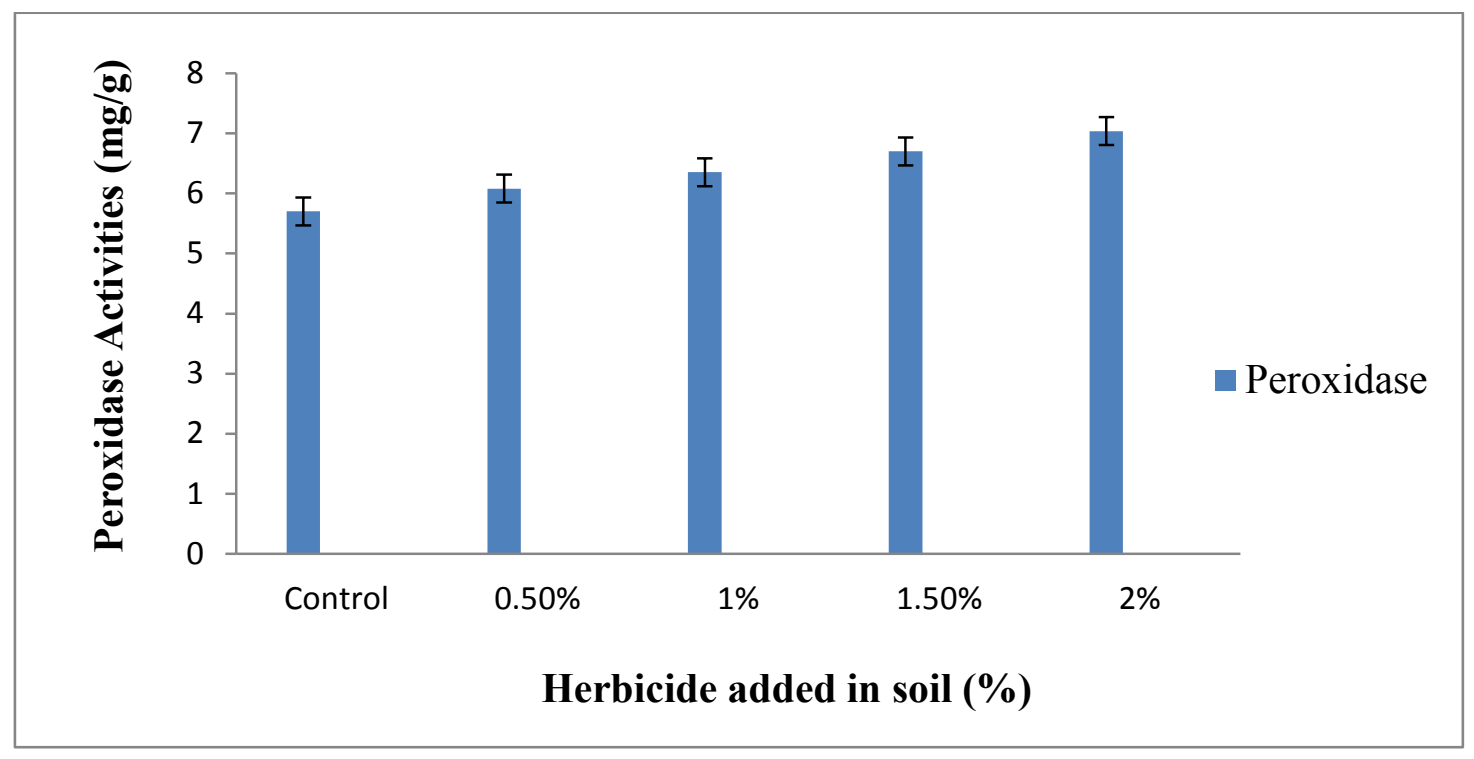

Fig. 5. Effect of different concentrations of herbicide (quizalafop-p-ethyl) on enzymes like peroxidase activities of Vigna mungo L.

Yield attributing characters like number of pods/ plant, seeds/plant and weight of 100 seeds (Fig. 6, $7 \& 8$ ) were decreased at higher concentration $(1 \%, 1.5 \%$ and $2 \%)$ of quizalafop-p-ethyl, whereas lower concentration $(0.5 \%)$ stimulated the yield attributing character of black gram.

The magnitude of decrease was a dose dependent manner under the highest concentration used $(2 \%)$ respectively. The decreased yield under high pesticide concentration in the soil is that it affected the microbial activity which ultimately led to the reduction of soil fertility and productivity (Amengor and Tetteh, 2008).

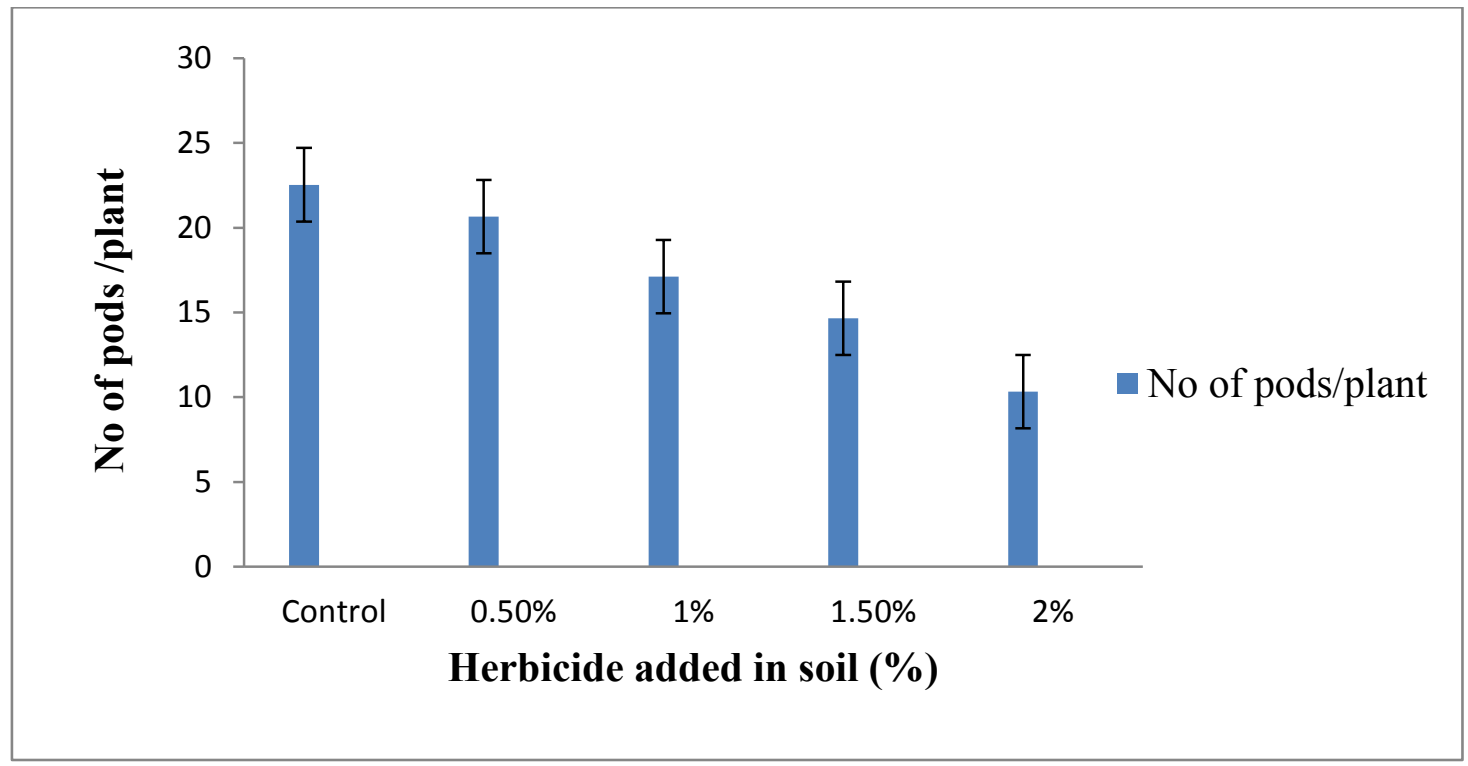

Fig. 6. Effect of different concentrations of herbicide (quizalafop-p-ethyl) on yield parameters (No of pods/plant) of Vigna mungo L. 


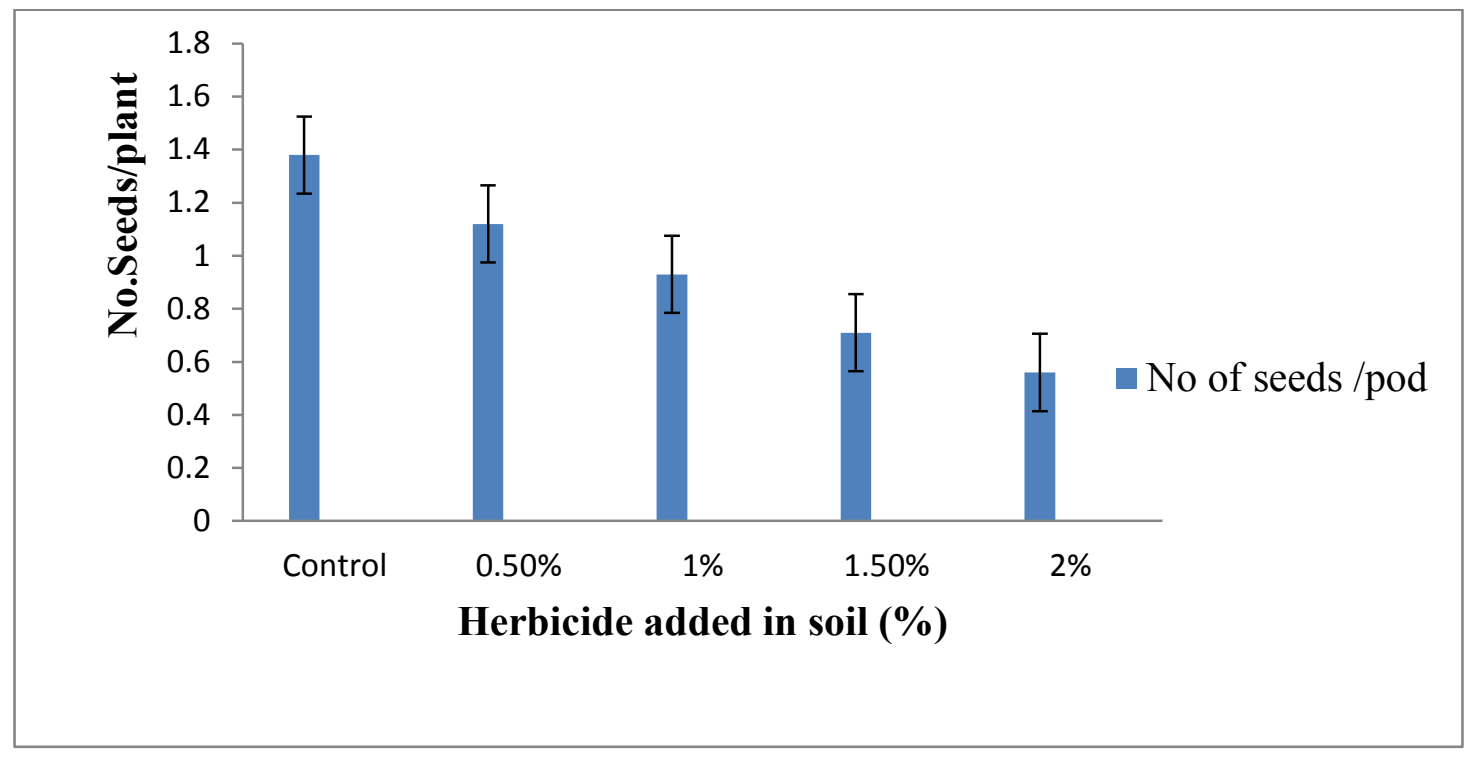

Fig. 7. Effect of different concentrations of herbicide (quizalafop-p-ethyl) on yield parameters (No.Seeds/Plant) of Vigna mungo L.

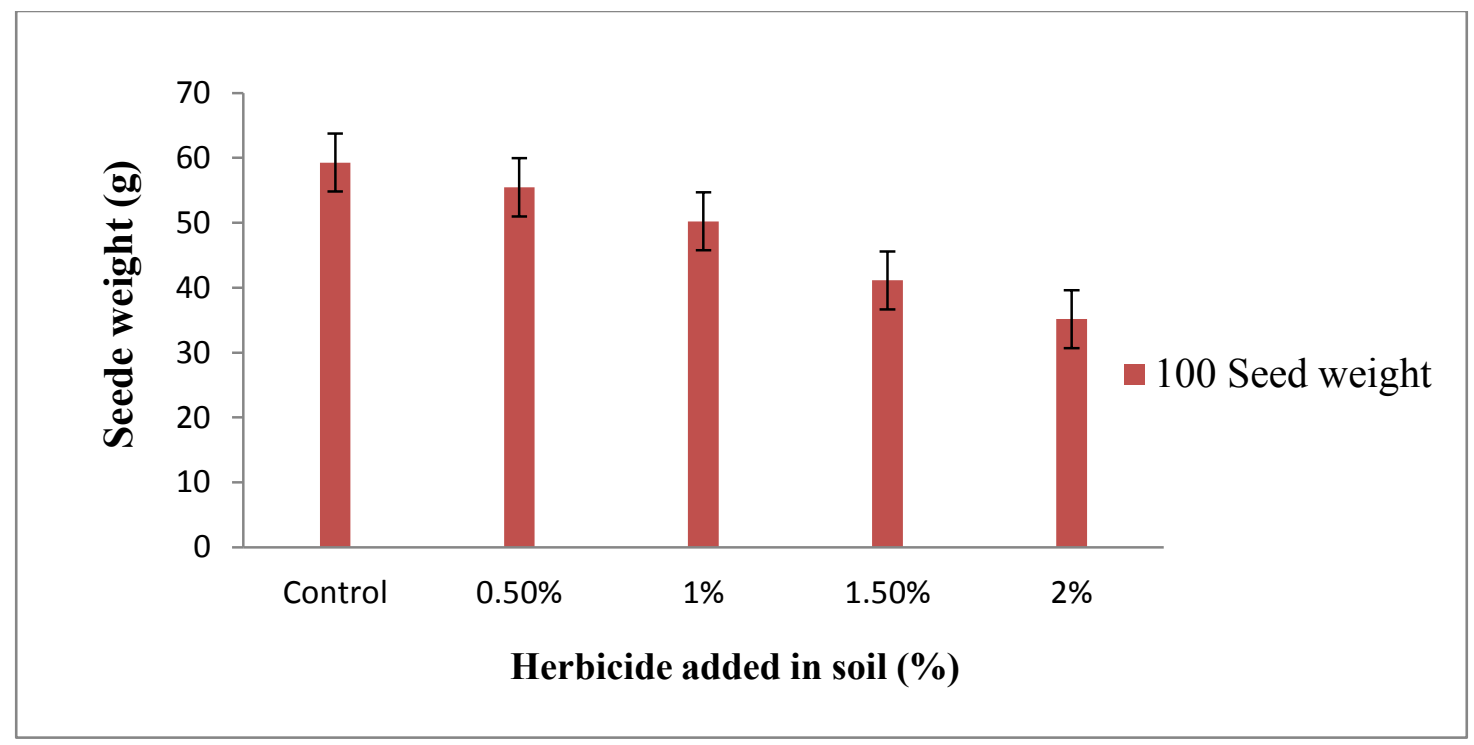

Fig. 8. Effect of different concentrations of herbicide (quizalafop-p-ethyl) on yield parameters (Seeds weight/Plant) of Vigna mungo L.

\section{CONCLUSION}

The study concusses that among the various concentration of herbicide (quizalafop-pethyl) treatment used in the experiment $0.5 \%$ is the safest for weed control in black gram (Vigna mungo L.) as it had least adverse effect on Growth, yield and enzymes activities of crop. 


\section{References}

[1] Ashiq M., V. Sattar, N. Ahmed, N. Muhammad (2007). Role of herbicides in crop production. Pub. Unique enterprises 17-A, Gulberg colony, Faisalabad, Pakistan. pp. 89.

[2] Arnon D. I., Plant physiol. 24 (1949) 1-15.

[3] Amengor M. G., F. M. Tetteh, West Afr. J. Appl. Ecol. 12 (2008) 45749-49202.

[4] Baroowa B., N. Gogoi, S. Paul, B. Sarma, Journal of Agricultural Sciences 57 (2012) $31-40$.

[5] Bunce N. J. (1993). Introduction to Environmental Chemistry, Wuerz Publishing Ltd., Winnipeg, Canada.

[6] Beltrame M. O., De Marco S. G., Marcovecchio J. E., Sci Total Environ 408 (2010) 531-536.

[7] Davies J., J. L. Honegger, F. G. Tencalla, G. Meregalli, P. Brain, J. R. Newman, H. F. Pitchford, Pest Manag. Sci. 59 (2003) 231-7.

[8] Galston A. W., R. Kaur, Proc. Nat. Acad. Sci. 45 (1959) 1587.

[9] Mohammed A. M. A, A. A. EI. Mashad, E. A. Kamel, Ann. Agric. Sci. 2 (2000) 457476.

[10] Prasad M. N. V., Freitas H., Fraenzle S., Wuenschmann S., Markert B., Environ. Pollut. 158 (2010) 18-23.

[11] Panse V. G., P. V. Sukhatme (1978). Statistical methods for agricultural workers. ICAR Publication, New Delhi, India.

[12] Sen R., Chakrabarti S., Curr. Sci. 97 (2009) 768-775.

[13] Sinha A. K., Anal. Biochem. 47(2) (1972) 389-394.

[14] Sestak Z. (1991). Leaf ontogeny and photosynthesis. In: Johnson CB(ed), Physiological processes limiting plant productivity. Butterworths, London, pp. 147-158.

[15] Yadav R. P., K. S. Yadavm, U. K. Srivastava, Indian Journal Agronomy 42(2) (1997) 24-26. 